\title{
Restriction Fragment Length Analysis of the Cytochrome $b$ Gene and Muscle Fatty Acid Composition Differentiate the Cryptic Flatfish Species Solea solea and Solea aegyptiaca
}

\author{
Evridiki Boukouvala, ${ }^{\dagger}, \boldsymbol{\Delta}$ Alessia Cariani, $\triangle, \boldsymbol{\Delta}$ Gregory E. Maes, ${ }^{\S}, \boldsymbol{\Delta}$ Rafael G. Sevilla, ${ }^{\#}$
} Véronique Verrez-Bagnis, ${ }^{\otimes, \boldsymbol{\Lambda}}, \boldsymbol{\nabla}$ Marc Jérôme, ${ }^{\otimes, \boldsymbol{\alpha}}, \nabla$ Ilaria Guarniero, ${ }^{\nabla}, \mathbf{\Lambda}$ Georgios Monios, ${ }^{\dagger}$ Fausto Tinti, $\triangle, \boldsymbol{\Lambda}$ Filip A.M. Volckaert, ${ }^{\S, \boldsymbol{\Lambda}}$ José M. Bautista, $, \boldsymbol{\Lambda}, \boldsymbol{\nabla}$ and Grigorios Krey, ${ }^{*, \dagger}, \boldsymbol{\Lambda}, \boldsymbol{\nabla}$

${ }^{\dagger}$ National Agricultural Research Foundation, Fisheries Research Institute, GR-64007 Nea Peramos, Kavala, Greece

$\triangle$ Department of Experimental Evolutionary Biology, University of Bologna, via Selmi 3, 40126 Bologna, Italy

${ }^{\S}$ Laboratory of Biodiversity and Evolutionary Genetics, Katholieke Universiteit Leuven, Ch. Deberiotstraat 32, B-3000 Leuven, Belgium

${ }^{\#}$ Department of Biochemistry and Molecular Biology IV, Facultad de Veterinaria, Universidad Complutense de Madrid, 28040 Madrid, Spain

${ }^{\otimes}$ Laboratoire Science et Technique de la Biomasse Marine, Ifremer, rue de l'Ile d'Yeu, B.P. 21105, 44311 Nantes Cedex 3, France

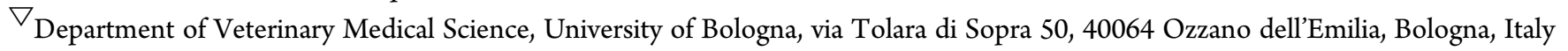

Supporting Information

ABSTRACT: Overlapping external morphometric characters easily confound the flatfishes Solea aegyptiaca and Solea solea (Soleidae) in areas of the Mediterranean Sea where both species live in sympatry. This leads to uncertainties in the fisheries and marketing of the species, in addition to misinterpretations in biogeography and conservation studies. This paper describes a simple restriction fragment length-based diagnostic test that differentiates S. solea from S. aegyptiaca, as well as from other species of the Soleidae family. Furthermore, the two species living in sympatry in the Gulf of Kavala (North Aegean Sea, Greece) present significant qualitative differences in muscle fatty acid composition, a property that can also be used to distinguish the two cryptic species.

KEYWORDS: Solea solea, Solea aegyptiaca, species diagnosis, cytochrome b gene, EcoR V restriction fragment length,

white muscle fatty acid composition

\section{INTRODUCTION}

The common sole (Solea solea Linnaeus, 1758), is an important fisheries resource in the northeastern Atlantic Ocean and Mediterranean Sea. ${ }^{1}$ Due to its high commercial value, its market has the potential for fraudulent (deliberate) substitution with fish of lesser value. ${ }^{2}$ This practice is facilitated in processed products, such as fresh or frozen filets, where species identification by morphological characters is not feasible. However, the unintentional substitution of $S$. solea can also occur when it is fished along with other Soleidae species sharing many common morphometric characters.

In the Mediterranean Sea $S$. solea co-occurs with two other Solea species, the Egyptian sole (Solea aegyptiaca Chabanaud, 1927) and the Senegalese sole (S. senegalensis Kaup, 1858). ${ }^{3}$ These species are morphologically similar and share the same habitat, that is, sandy/muddy bottoms in marine or brackish waters, ${ }^{4}$ resulting in identification issues, especially in areas where they live in sympatry. Hence, solely on the basis of morphometric data, the species status of $S$. aegyptiaca has been contested and synonomy with $S$. solea has been proposed. ${ }^{5}$ However, early biochemical genetic studies, ${ }^{6-8}$ as well as more recent cytochrome $b$ (cyt $b$ ) and cytochrome oxidase subunit I (COI) gene-based phylogenies, ${ }^{2,9}$ along with the latest taxonomic revision of the genus Solea, ${ }^{10}$ all argue for maintaining $S$. aegyptiaca as a distinct species.

In contrast to $S$. solea, which has a Mediterranean-wide distribution, ${ }^{11}$ reports of the occurrence of $S$. aegyptiaca limit the range of the species along the Mediterranean North African coast and the Gulf of Lion, in the northwestern Mediterranean Sea, ${ }^{6,8}$ as well as in the southernmost extremity of the Adriatic Sea. ${ }^{3}$ However, older sources report the presence of the species also in the upper part of the Adriatic Sea. ${ }^{12}$ Furthermore, the species does not appear in the fisheries statistics of any Mediterranean country with the exception of Egypt, where it constitutes an important fisheries resource. ${ }^{13}$

On the basis of the study of the cyt $b$ gene sequence variation of Solea spp. specimens, we report herein the presence of $S$. aegyptiaca in sympatry with $S$. solea in the Gulf of Kavala (North Aegean Sea, Greece). The identification of S. aegyptiaca in the northeastern part of the Mediterranean Sea, where it is confounded with $S$. solea and is being marketed as such, implies

Received: March 22, 2012

Revised: July 17, 2012

Accepted: July 18, 2012

Published: July 18, 2012 
a potentially Mediterranean-wide distribution of the species. This in turn raises concerns about the fisheries of the species at the local and regional levels and traceability in the food market. ${ }^{14}$ Furthermore, it also emphasizes the lack of knowledge on ecological aspects of both species, such as habitat preference, resilience to anthropogenic impacts, and reproductive isolation. Indeed, hybridization between $S$. aegyptiaca and $S$. solea is possible, as recently documented between S. aegyptiaca and Solea senegalensis in the Gulf of Tunis, where the two species live in sympatry. ${ }^{8,15}$ Therefore, it is important that simple control tools are available to scientists and control authorities to differentiate unambiguously $S$. solea from $S$. aegyptiaca, especially in cases when identification by morphometric characters is not possible. Furthermore, in the case of unintentional species substitution, the qualitative traits of $S$. aegyptiaca of interest to consumers have to be evaluated and compared to those of $S$. solea.

We propose a simple and rapid diagnostic test, based on the PCR amplification of the cyt $b$ gene followed by restriction fragment length analysis, to differentiate $S$. solea from $S$. aegyptiaca as well as from other Mediterranean Soleidae. Furthermore, we examine and compare the fatty acid composition, that is, an important indicator of nutritional quality, in the white muscle tissue of both species. We demonstrate that tissue fatty acid composition also differentiates the two species living in sympatry in the Gulf of Kavala.

\section{MATERIALS AND METHODS}

Fish and Tissue Samples. Fish samples were collected from the Gulf of Kavala, North Aegean Sea, Greece, in 2008, 2009, and 2010 within the framework of the FishPopTrace research project (http:// fishpoptrace.jrc.ec.europa.eu/). Specifically, the 2008 sample included 3 S. aegyptiaca specimens, of which 2 were female; the 2009 sample included $16 \mathrm{~S}$. solea specimens (8 female and 8 male) and $11 \mathrm{~S}$. aegyptiaca (4 female and 7 male); the 2010 sample consisted of $12 \mathrm{~S}$. solea fish, of which 6 were female and 6, male. Coordinates of sample collection localities are available in the FishPopTrace database (GISbased monitoring, http://fishpoptrace.jrc.ec.europa.eu/map/ geobrowser.html). Additional specimen details are summarized in Table S1 of the Supporting Information. Fin clips and muscle tissue were obtained for DNA extraction and fatty acid analysis, respectively, and were stored appropriately (fin clips in ethanol, muscle deep frozen) until analyses.

DNA Extraction and Analyses. Total DNA was extracted from fin clips and/or muscle tissue with the DNeasy tissue kit (QIAGEN, Hilden, Germany) according to the manufacturer's instructions. The $5^{\prime}$ end of the $S$. aegyptiaca cyt $b$ gene was amplified from $0.5 \mu \mathrm{g}$ of genomic DNA using $200 \mathrm{nM}$ of each Sol-CYTBF1 (5'-ACA ATG ACT AGT CTA CGA AAA TCC) and CytBI-5R (5'-GGT CTT TGT AGG AGA AGT ATG GGT GGA A) primer and 1 unit of Phusion DNA polymerase (Finnzymes, Vantaa, Finland) in a $50 \mu \mathrm{L}$ reaction volume containing $1.5 \mathrm{mM} \mathrm{MgCl}_{2}$ and $0.2 \mathrm{mM}$ of each dNTP. Reaction conditions involved an initial denaturation step at $98^{\circ} \mathrm{C}(30$ s), followed by 35 cycles of $98^{\circ} \mathrm{C}(10 \mathrm{~s})-57^{\circ} \mathrm{C}(30 \mathrm{~s})-72{ }^{\circ} \mathrm{C}(35 \mathrm{~s})$ and a final elongation step of $7 \mathrm{~min}$ at $72^{\circ} \mathrm{C}$. The $3^{\prime}$ end of the cyt $b$ gene was amplified with $200 \mathrm{nM}$ of each of the Cytb3-814bp-IG ( $5^{\prime}$ CTT CGT AGG ATA CGT CCT CCC-3') and Sol-CYTBR1 (5'GGC GCT CTA ACA CTG AGC TAC) primers and 1 unit of Taq DNA polymerase (Invitrogen, Paisley, UK) in a $40 \mu \mathrm{L}$ reaction volume containing $1.5 \mathrm{mM} \mathrm{MgCl} 2$ and $0.2 \mathrm{mM}$ of each dNTP. Reaction conditions involved an initial denaturation step for $3 \mathrm{~min}$ at $94{ }^{\circ} \mathrm{C}$, followed by 35 cycles of $94{ }^{\circ} \mathrm{C}(45 \mathrm{~s})-59{ }^{\circ} \mathrm{C}(30 \mathrm{~s})-72{ }^{\circ} \mathrm{C}(90 \mathrm{~s})$ and a final extension step of $7 \mathrm{~min}$ at $72{ }^{\circ} \mathrm{C}$. The cyt $b$ gene from $S$. solea, Pegusa lascaris (Risso, 1810), and Synapturichthis kleinii (Risso, 1827) was PCR-amplified as described in the corresponding entries in the FishTrace database (www.fishtrace.org). ${ }^{16}$ PCR products were column purified (PCR purification kit, QIAGEN) before sequencing and/or
EcoRV (Minotech, Heraklion, Greece) restriction analysis. All sequencing was performed by a commercial sequence service provider (Macrogen Europe, Amsterdam, The Netherlands) employing the same primers used for the amplification of the cyt $b$ gene. PCR products and their EcoRV fragments were analyzed by agarose gel electrophoresis $(1.5 \%)$ and visualized by ethidium bromide staining.

Sequence alignment and restriction enzyme cleavage site searches were performed with the OMIGA software package (Accelerys, Cambridge, UK). All reference cyt $b$ sequences of Soleidae (a total of 120 sequences) were derived within the framework of the FishTrace project (www.fishtrace.org) and correspond to taxonomically validated specimens. These included $96 \mathrm{~S}$. solea sequences, from fish originating from the North Aegean Sea (20 sequences, GENBANK accession nos. JF509431-JF509450), the western Mediterranean (15 sequences, GENBANK accession nos. JN561668-JN561682), the Bay of Biscay (18 sequences, GENBANK accession nos. JF969239-JF969252), the North Sea (20 sequences, GENBANK accession nos. JN561627JN561646), and the Skagerrak (21 sequences, GENBANK accession nos. JN561647-JN561661). The remaining 24 sequences included four Senegalese sole sequences ( $S$. senegalensis, two from the western Mediterranean and two from the Canary Islands, GENBANK accession nos. EF439590-1 and EF427601-2, respectively), eight sand sole sequences ( $P$. lascaris, two from the North Aegean, two from the western Mediterranean, two from the Canary Islands, and two from the Bay of Biscay with GENBANK accession nos. EU036472-3, EF439565-6, EF392603-4, and EU224070-1, respectively), six Klein's sole sequences ( $S$. kleinii, two from the North Aegean, two from the western Mediterranean, and two from the Canary Islands with GENBANK accession nos. EU036510-1, EF439603-4, and EF392623-4, respectively), and six thickback sole sequences (Microchirus variegatus Donovan, 1808, two from the Western Mediterranean, two from the Cantabric Sea, and two from the Bay of Biscay with GENBANK accession nos. EF439550-1, EF427582-3, and EU224062-3, respectively).

For the amplification of the $S$. aegyptiaca rhodopsin gene nested PCR was used. The primer set for the first amplification step was Rod F2B (5'-CTC TGC AAG CCC ATC AGC AAC TTC CG) and Rod 5R (5'-GGT GGT GAT CAT GCA GTG GCG GAA) and for the second Rod F2 (5'-AGC AAC TTC CGC TTC GGA GAG AA) and Rod 4R (5'-CTG CTT GTT CAT GCA GAT GTA GAT). The PCR conditions for both steps were as previously described by Sevilla et al. (protocol 30). ${ }^{16}$ The S. aegyptiaca rhodopsin sequences were deposited in GENBANK under accession nos. JX292784-5.

Distance divergence between Soleidae sequences at the cyt $b$ and the rhodopsin loci was estimated with the $p$-distance method (bootstrap validated, 1000 replications) using the MEGA5 software program. ${ }^{17}$

Chemical Analysis. From each fish, the skin from the eyed side was removed and a piece of white muscle tissue $(5-8 \mathrm{~g})$, above the lateral line and near the caudal fin, was obtained and lyophilized overnight in a Christ alpha 2-4 freeze-dryer (Martin Christ $\mathrm{GmbH}$, Osterode am Harz, Germany). Dehydrated tissue ( $0.2 \mathrm{~g})$ was ground to fine powder, and lipids were extracted according to the Folch method. ${ }^{8}$ One milligram of total lipid was used for the transesterification of fatty acids, as described by Falch et al., ${ }^{19}$ and tissue fatty acid composition was determined by gas chromatography on a Hewlett-Packard 5809 series II gas chromatograph, equipped with a flame ionization detector (FID) and a $60 \mathrm{~m}, 0.25 \mathrm{~mm}$ internal diameter, BPX-70 capillary column (SGE Analytical Science, Ringwood, Australia). The inlet was set at the split mode (split 1:60) and the inlet temperature at $320{ }^{\circ} \mathrm{C}$. The detector temperature was set at $300{ }^{\circ} \mathrm{C}$. Helium was used as carrier gas and nitrogen as auxiliary gas (flow rate at $36 \mathrm{~mL} \mathrm{~min}{ }^{-1}$ ). FID gases were hydrogen (flow rate $=30$ $\mathrm{mL} \mathrm{min}^{-1}$ ) and compressed air (flow rate $\left.=330 \mathrm{~mL} \mathrm{~min}{ }^{-1}\right)$. The program used to separate the fatty acid methyl esters included a $2 \mathrm{~min}$ hold time at $50{ }^{\circ} \mathrm{C}$, temperature increase from 50 to $150{ }^{\circ} \mathrm{C}$ at a rate of $20{ }^{\circ} \mathrm{C} \min ^{-1}$ and from 150 to $230{ }^{\circ} \mathrm{C}$ at a rate of $1.5{ }^{\circ} \mathrm{C} \min ^{-1}$, followed by a $3 \mathrm{~min}$ hold time at $230{ }^{\circ} \mathrm{C}$. For peak identification, solutions of reference substances ( 37 Component FAME Mix, SigmaAldrich, St. Louis, MO, USA) were analyzed under the same 
conditions, and their retention times and chromatograms were compared to those of the target sample. In each sample, heptadecanoic acid (C 17:0, Sigma-Aldrich) was used as internal standard. The contribution of each identified compound was expressed as the percentage of its peak area to the total area of all peaks eluted in each chromatogram. Peak areas were calculated with Hewlett-Packard GCChem Station software. A total of 28 S. solea specimens (14 male and 14 female, corresponding to the 2009 and 2010 samples) and $11 \mathrm{~S}$. aegyptiaca specimens ( 7 male and 4 female, corresponding to the 2009 sample) were analyzed.

Statistical Analysis. Significant differences in muscle fatty acid content and composition were determined at the individual fatty acid level between the two species by the $t$ test for independent variables by group. Homogeneity of variances was tested by the Levene and/or the Brown-Forsyth tests. For fatty acids exhibiting not normal distribution, the nonparametric Kolmogorov-Smirnov two-sample test was used. Sex-dependent differences within or between the two species were determined by factorial ANOVA, followed by Tukey's post test. Homogeneity of variances was tested with Levene's test for ANOVA. The nonparametric Kruskal-Wallis ANOVA test was applied to those fatty acids not conforming to the homogeneity of variance assumption. For species differentiation based on muscle fatty acid composition discriminant function analysis (DA) was applied. This analysis is used to determine the variables or set of characters that discriminate between naturally occurring groups. For forward-step DA, the fatty acids for which means were affected by extreme values, rendering their statistical significance unreliable, were excluded. $K$-fold cross-validation and repeated random subsampling validation were performed on the data set that resulted from forward step DA. $K$-fold cross-validation allows prediction for a given observation once left out of the estimation sample. In repeated random subsampling validation, after random splitting of the data set to "training" and "validation" samples, the training sample is used to build the model and the validation sample to assess its predictive accuracy. Validation samples ranging from 20 to $50 \%$ of total observations were used in this analysis. All analyses were performed with the Statistica 7 software package (StatSoft, Tulsa, OK, USA), except for the cross-validation for which the XLSTAT application (Addinsoft, Paris, France) was used.

\section{RESULTS AND DISCUSSION}

Presence of S. aegyptiaca in the North Aegean Sea. Initial evidence for the presence of S. aegyptiaca in the North Aegean Sea came from sequencing of the $5^{\prime}$-end of the cyt $b$ gene of presumed S. solea specimens, collected in the Gulf of Kavala in 2008. Three sequences (GENBANK accession nos. JN225430-JN225432) diverged significantly, that is, $>11 \%$, from the sequence of validated $S$. solea specimens from the same geographic area (GENBANK accession nos. JF509431JF509450). In contrast, they were $100 \%$ identical to the published S. aegyptiaca sequence ${ }^{2,9}$ (GENBANK accession nos. AF289718 and EU513872-74, respectively). An additional 11 fish collected in 2009 were identified at the cyt $b$ locus as $S$. aegyptiaca (GENBANK accession nos. JN225426-JN225429 and JN248266-JN24871), providing strong support for an established population of this species in the Gulf of Kavala, where it co-occurs with S. solea.

Development of a Molecular Diagnostic Test for $S$. solea. The presence of $S$. aegyptiaca co-occurring with $S$. solea in the North Aegean Sea, and potentially in other Mediterranean areas where it is currently confounded with $S$. solea, highlights the need for the development of a rapid, costefficient, and readily applicable diagnostic tool to reliably discriminate between the two species. To achieve this, the cyt $b$ gene of $S$. solea was scanned, along with the newly generated $S$. aegyptiaca cyt $b$ sequences for the presence/absence of cleavage sites of common restriction endonucleases. To account for intraspecific variability at the cyt $b$ gene, we included the sequences of 96 additional S. solea individuals in this analysis, originating from different Mediterranean and Atlantic areas (see Materials and Methods for the geographic origin of sequences used and corresponding GENBANK accession nos.). This in silico restriction approach revealed that all $S$. solea sequences, irrespective of geographic origin, contained a single $E c o R V$ cleavage site at position 413 of the gene, which was absent in the $S$. aegyptiaca sequences analyzed (Figure 1A). We further

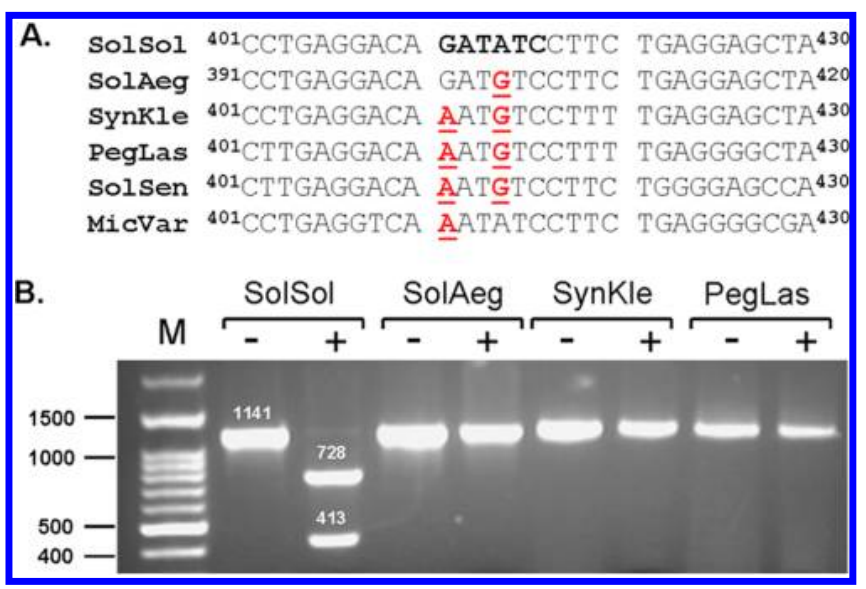

Figure 1. The presence of an $E c o$ RV restriction endonuclease site in the cyt $b$ gene differentiates $S$. solea from other Soleidae species. (A) Sequence comparison of the cyt $b$ gene of $S$. solea (SolSol), $S$. aegyptiaca (SolAeg), S. kleinii (SynKle), P. lascaris (PegLas), S. senegalensis (SolSen), and M. variegatus (MicVar). Base numbering is according to GENBANK entries EU264020, JN225426, EU036510, EU036472, EF439591, and EF439551 for SolSol, SolAeg, SynKle, PegLas, SolSen, and MicVar, respectively. The EcoRV site in the SolSol sequence is indicated by bold letters, and diverging nucleotides in the sequences of the other species are underlined. (B) Agarose gel electrophoresis of the entire PCR-amplified cyt $b$ gene $(1141 \mathrm{nt})$ of different Soleidae species in the absence $(-)$ or presence $(+)$ of the $E c o R V$ restriction endonuclease. Species names are as in panel A. The size of the SolSol fragments is indicated. $M$ is the molecular size marker (100 bp DNA Ladder, Nippon Genetics Europe, Düren, Germany).

examined whether this diagnostic feature could also be used to differentiate S. solea from other Soleidae species, in addition to $S$. aegyptiaca, that are, or could be, used as commercial substitutes of $S$. solea. Thus, the analysis was expanded to include the cyt $b$ gene sequence of four $S$. senegalensis, of eight P. lascaris, of six S. kleinii, and of six M. variegates (see Materials and Methods for the geographic origin of sequences used and corresponding GENBANK accession nos). As was the case for $S$. aegyptiaca, none of the sequences of the above species contained the EcoRV cleavage site (Figure 1A).

To confirm the results of the in silico analysis and, thus, to validate the potential of this unique $S$. solea feature as a diagnostic tool, the sequences encoding the cyt $b$ gene of $S$. solea, S. aegyptiaca, S. kleinii, and P. lascaris were PCR-amplified and subjected to $E c o R V$ digestion. As expected, the restriction endonuclease cleaved only the $S$. solea cyt $b$ gene, resulting in two fragments of 413 and 728 bp (Figure 1B). Hence, the above results demonstrate that this rapid and cost-efficient test, which eliminates the need for extensive sequencing effort, can be effectively used to differentiate $S$. solea from S. aegyptiaca, as well as from other Soleidae species, in cases when identification is not possible through morphological characters. This in turn 
Table 1. White Muscle Tissue Fatty Acid Composition (Percent Total Fatty Acids) in the S. solea (SolSol) and S. aegyptiaca (SolAeg) Samples ${ }^{a}$

\begin{tabular}{|c|c|c|c|c|c|c|c|}
\hline \multirow[b]{2}{*}{ FA } & \multicolumn{2}{|c|}{$\% \mathrm{FA}$} & \multirow[b]{2}{*}{$p$} & \multirow[b]{2}{*}{ FA } & \multicolumn{2}{|c|}{$\% \mathrm{FA}$} & \multirow[b]{2}{*}{$p$} \\
\hline & $\begin{array}{c}\text { SolSol } \\
(n=28)\end{array}$ & $\begin{array}{l}\text { SolAeg } \\
(n=11)\end{array}$ & & & $\begin{array}{c}\text { SolSol } \\
(n=28)\end{array}$ & $\begin{array}{l}\text { SolAeg } \\
(n=11)\end{array}$ & \\
\hline C14:0 & $1.42 \pm 0.45$ & $0.96 \pm 0.17$ & $<0.03$ & $\mathrm{C} 22: 0$ & $0.32 \pm 0.20$ & $0.18 \pm 0.06$ & $<0.05$ \\
\hline C14:1 & $0.26 \pm 0.10$ & $0.11 \pm 0.03$ & $<0.01$ & C22:1 n-11 & $0.34 \pm 0.20$ & $0.25 \pm 0.07$ & NS \\
\hline C15:0 & $0.77 \pm 0.27$ & $0.79 \pm 0.11$ & NS & C20:5 n-3 & $4.68 \pm 1.24$ & $2.92 \pm 0.77$ & $<0.01$ \\
\hline C15:1 & $0.21 \pm 0.05$ & $0.24 \pm 0.07$ & NS & C23:0 & $0.28 \pm 0.16$ & $0.13 \pm 0.04$ & $<0.01$ \\
\hline C16:0 & $19.55 \pm 1.72$ & $22.73 \pm 1.57$ & $<0.01$ & $\mathrm{C} 22: 3 \mathrm{n}-3$ & $2.50 \pm 0.46$ & $2.87 \pm 1.13$ & NS \\
\hline $\mathrm{C} 16: 1 \mathrm{n}-7$ & $3.44 \pm 1.05$ & $2.01 \pm 0.41$ & $<0.01$ & C22:4 n-6 & $3.02 \pm 0.87$ & $3.96 \pm 0.84$ & $<0.01$ \\
\hline $\mathrm{C} 17: 1$ & $1.15 \pm 0.28$ & $1.05 \pm 0.23$ & NS & C24:1 n-9 & $0.92 \pm 0.39$ & $0.36 \pm 0.11$ & $<0.01$ \\
\hline C18:0 & $6.16 \pm 0.73$ & $8.07 \pm 0.63$ & $<0.01$ & $\mathrm{C} 22: 5 \mathrm{n}-3$ & $7.12 \pm 1.17$ & $4.41 \pm 0.56$ & $<0.01$ \\
\hline C18:1 n-9t & $1.96 \pm 1.68$ & $0.75 \pm 0.99$ & $<0.05$ & $\mathrm{C} 22: 6 \mathrm{n}-3$ & $19.76 \pm 4.81$ & $21.29 \pm 3.70$ & NS \\
\hline $\mathrm{C} 18: 1 \mathrm{n}-9 \mathrm{c}$ & $8.99 \pm 0.89$ & $11.56 \pm 1.02$ & $<0.01$ & & & & \\
\hline C18:1 n-7 & $2.25 \pm 0.39$ & $3.60 \pm 0.71$ & $<0.01$ & total SAEA & $29.25 \pm 1.72$ & $33.14 \pm 1.42$ & $<0.01$ \\
\hline C18:2 n-6t & $0.24 \pm 0.08$ & $0.13 \pm 0.07$ & $<0.01$ & total MUFA & $19.93 \pm 2.34$ & $20.32 \pm 1.30$ & NS \\
\hline $\mathrm{C} 18: 2 \mathrm{n}-6 \mathrm{c}$ & $0.61 \pm 0.10$ & $1.00 \pm 0.10$ & $<0.01$ & total PUFA & $49.93 \pm 2.66$ & $45.76 \pm 2.21$ & $<0.01$ \\
\hline C18:3 n-6 & $0.44 \pm 0.25$ & $0.20 \pm 0.14$ & $<0.01$ & total $n-3$ & $35.23 \pm 3.96$ & $32.25 \pm 2.41$ & $<0.05$ \\
\hline C20:0 & $0.77 \pm 0.37$ & $0.29 \pm 0.08$ & $<0.01$ & total $n-6$ & $14.70 \pm 2.37$ & $13.51 \pm 1.87$ & NS \\
\hline C18:4 n-3 & $0.80 \pm 0.42$ & $0.51 \pm 0.22$ & $<0.05$ & $n-3 / n-6$ & $2.50 \pm 0.73$ & $2.44 \pm 0.45$ & NS \\
\hline C20:1 n-9 & $0.41 \pm 0.14$ & $0.41 \pm 0.18$ & NS & & & & \\
\hline C20:2 n-6 & $0.17 \pm 0.10$ & $0.10 \pm 0.17$ & $<0.01$ & total fat $(\%)$ & $3.60 \pm 0.97$ & $3.39 \pm 0.44$ & NS \\
\hline$C 20: 3 n-6$ & $0.26 \pm 0.08$ & $0.42 \pm 0.21$ & $<0.01$ & & & & \\
\hline C20:3 n-3 & $0.41 \pm 0.17$ & $0.25 \pm 0.05$ & $<0.01$ & & & & \\
\hline C20:4 n-6 & $9.98 \pm 2.30$ & $7.76 \pm 1.59$ & $<0.01$ & & & & \\
\hline
\end{tabular}

${ }^{a}$ Values are the mean \pm SD. Column " $p$ ” presents the significant differences between species $(t$ test). NS indicates nonsignificant differences.

can contribute to the control of potential fraudulent and unintentional substitutions in S. solea fisheries and marketing and, consequently, protect both consumers and businesses. Furthermore, the identification of $S$. aegyptiaca in the North Aegean Sea in sympatry with $S$. solea suggests that the geographical distribution of the species in the Mediterranean Sea needs reappraisal. Moreover, it underscores the need for improved understanding of the ecological and biological aspects of the two species, such as their resilience to anthropogenic impacts and their potential for interspecific hybridization. With respect to the interspecific hybridization issue, the limitations of diagnostic tests based on mitochondrial markers, which identify only the maternal lineage, are obvious. Therefore, development and use of nuclear markers is necessary to unambiguously address this question. Relevant to this, our preliminary analysis of the rhodopsin gene in a limited number of the abovedescribed $S$. aegyptiaca specimens revealed a modest degree of sequence divergence ( $2 \%$ ) from the S. solea gene, that is, within the levels expected for closely related congeneric species. ${ }^{16}$ Thus, the rhodopsin gene and the $S$. solea-specific SNP markers that we are currently developing represent tools that can be applied toward resolving this issue.

Fatty Acid Profile Analysis of White Muscle Tissue of the Two Species. The fatty acid composition of Mediterranean $S$. solea has been determined before, ${ }^{20-22}$ but to our knowledge this has not been done for S. aegyptiaca. Therefore, to evaluate and compare the nutritional value of the two sympatric species in the North Aegean Sea, the fatty acid composition of the white muscle tissue was determined in a total of 28 S. solea specimens and 11 S. aegyptiaca specimens. In each species a total of 30 fatty acids (FA) were identified and quantified (Table 1). Species-specific differences at the individual FA level were determined by the $t$ test for independent samples. Significant between-species differences were observed in $23 \mathrm{FA}$. Of the seven FA that did not present differences in the two species, five were minor components of total FA, that is, each representing $<1 \%$ of total FA, with the remaining two being docosahexaenoic acid (C22:6n-3, DHA) and docosatrienoic acid (C22:3 n-3) (Table 1). This comparison also revealed that $S$. aegyptiaca muscle contained significantly higher levels of total saturated FA (SAFA), whereas $S$. solea was richer in total polyunsaturated FA (PUFA), as well as in total n-3 FA. Accordingly, the n-3/n-6 FA ratio, an important indicator for human nutrition, ${ }^{23}$ was higher in the $S$. solea fish as compared to the S. aegyptiaca sample. No significant differences were observed in the muscle total fat content of the two species (Table 1).

In addition to the unbalanced sample size between the two species $(n=28$ and $n=11$ for S. solea and S. aegyptiaca, respectively), the $S$. solea sample consisted of 14 female and 14 male fish, whereas only 4 S. aegyptiaca specimens were female. Furthermore, in contrast to the female $S$. solea fish, which were spawning at sampling time, the $S$. aegyptiaca sample and the male S. solea fish were all nonspawning (Supporting Information, Table S1). Thus, to evaluate potential effects of sex and/or reproductive stage on the tissue FA composition, the analysis was repeated by considering both species and sex as categorical predictors in factorial ANOVA. As shown in Table 2 , between-species differences in tissue content of several fatty acids were directly dependent on sex/reproductive stage in the S. solea sample. Specifically, the observed species differences in tissue content for myristic (C14:0), palmitoleic (C16:1 n-7), eicosanoic (C20:0), arachidonic (C20:4 n-6, ArA), and eicosapentaenoic (C20:5 n-3, EPA) acids were solely due to the higher level of these FA in the female $S$. solea fish. In addition, the significantly lower DHA content in female $S$. solea fish, as compared to both $S$. aegyptiaca and male $S$. solea, was masked in the between-species comparative analysis. Further- 
Table 2. White Muscle Tissue Fatty Acid Composition (Percent Total Fatty Acids) in the Female (F) and Male (M) Specimens of S. solea (SolSol) and S. aegyptiaca (SolAeg) ${ }^{a}$

\begin{tabular}{|c|c|c|c|c|c|}
\hline & \multicolumn{4}{|c|}{$\%$ FA } & \multirow[b]{2}{*}{$\begin{array}{c}\text { Spp.\& sex } \\
\boldsymbol{p}<\mathbf{0 . 0 1}\end{array}$} \\
\hline & $\begin{array}{l}\text { SolSol-F } \\
(n=14)\end{array}$ & $\begin{array}{l}\text { SolSol-M } \\
(n=14)\end{array}$ & $\begin{array}{c}\text { SolAeg-F } \\
(n=4)\end{array}$ & $\begin{array}{c}\text { SolAeg-M } \\
(n=7)\end{array}$ & \\
\hline C14:0 & $1.75 \pm 0.40$ & $1.08 \pm 0.13$ & $0.83 \pm 0.12$ & $1.04 \pm 0.15$ & $a, b, c$ \\
\hline C14:1 & $0.33 \pm 0.09$ & $0.19 \pm 0.07$ & $0.09 \pm 0.02$ & $0.11 \pm 0.03$ & $a, b, c$ \\
\hline C15:0 & $0.68 \pm 0.25$ & $0.86 \pm 0.26$ & $0.83 \pm 0.12$ & $0.76 \pm 0.11$ & NS \\
\hline C15:1 & $0.21 \pm 0.05$ & $0.21 \pm 0.06$ & $0.19 \pm 0.05$ & $0.26 \pm 0.07$ & NS \\
\hline C16:0 & $18.90 \pm 1.66$ & $20.19 \pm 1.57$ & $22.04 \pm 1.60$ & $23.12 \pm 1.52$ & $\mathrm{~b}, \mathrm{c}, \mathrm{e}$ \\
\hline Cc16:1 n-7 & $4.29 \pm 0.77$ & $2.59 \pm 0.37$ & $1.81 \pm 0.23$ & $2.10 \pm 0.47$ & $a, b, c$ \\
\hline C17:1 & $1.23 \pm 0.34$ & $1.08 \pm 0.18$ & $1.03 \pm 0.29$ & $1.06 \pm 0.21$ & NS \\
\hline C18:0 & $5.67 \pm 0.57$ & $6.64 \pm 0.51$ & $8.28 \pm 0.19$ & $7.95 \pm 0.78$ & $\mathrm{a}, \mathrm{b}, \mathrm{c}, \mathrm{d}, \mathrm{e}$ \\
\hline $\mathrm{C} 18: 1 \mathrm{n}-9 \mathrm{t}$ & $1.75 \pm 1.45$ & $2.17 \pm 1.91$ & $1.25 \pm 1.64$ & $0.46 \pm 0.17$ & NS \\
\hline C18:1 n-9c & $9.17 \pm 0.83$ & $8.80 \pm 0.95$ & $11.75 \pm 0.92$ & $11.46 \pm 1.13$ & $\mathrm{~b}, \mathrm{c}, \mathrm{d}, \mathrm{e}$ \\
\hline C18:1 n-7 & $2.21 \pm 0.32$ & $2.29 \pm 0.45$ & $3.63 \pm 0.77$ & $3.59 \pm 0.73$ & $\mathrm{~b}, \mathrm{c}, \mathrm{d}^{*}, \mathrm{e}$ \\
\hline $\mathrm{C} 18: 2 \mathrm{n}-6 \mathrm{t}$ & $0.26 \pm 0.10$ & $0.22 \pm 0.05$ & $0.12 \pm 0.08$ & $0.14 \pm 0.07$ & $b, c, d, e$ \\
\hline C18:2 n-6c & $0.61 \pm 0.10$ & $0.61 \pm 0.10$ & $1.07 \pm 0.06$ & $0.95 \pm 0.09$ & $\mathrm{~b}, \mathrm{c}, \mathrm{d}, \mathrm{e}$ \\
\hline C18:3 n-6 & $0.45 \pm 0.27$ & $0.44 \pm 0.23$ & $0.13 \pm 0.05$ & $0.24 \pm 0.16$ & NS \\
\hline C20:0 & $1.10 \pm 0.14$ & $0.45 \pm 0.19$ & $0.30 \pm 0.11$ & $0.29 \pm 0.07$ & $a, b, c$ \\
\hline C18:4 n-3 & $0.89 \pm 0.53$ & $0.72 \pm 0.28$ & $0.47 \pm 0.28$ & $0.54 \pm 0.19$ & NS \\
\hline C20:1 n-9 & $0.47 \pm 0.16$ & $0.35 \pm 0.09$ & $0.40 \pm 0.21$ & $0.41 \pm 0.18$ & NS \\
\hline$C 20: 2 n-6$ & $0.23 \pm 0.08$ & $0.11 \pm 0.08$ & $0.05 \pm 0.03$ & $0.05 \pm 0.04$ & $a^{*}, b, c$ \\
\hline C20:3 n-6 & $0.29 \pm 0.07$ & $0.23 \pm 0.07$ & $0.46 \pm 0.25$ & $0.39 \pm 0.19$ & NS \\
\hline$C 20: 3 n-3$ & $0.51 \pm 0.13$ & $0.31 \pm 0.15$ & $0.25 \pm 0.05$ & $0.24 \pm 0.05$ & a, c \\
\hline C20:4 n-6 & $11.77 \pm 1.38$ & $8.19 \pm 1.49$ & $9.22 \pm 1.25$ & $6.93 \pm 1.10$ & $a, b, c$ \\
\hline $\mathrm{C} 22: 0$ & $0.44 \pm 0.20$ & $0.20 \pm 0.13$ & $0.18 \pm 0.04$ & $0.17 \pm 0.07$ & $a, b^{*}, c$ \\
\hline C22:1 n-11 & $0.45 \pm 0.20$ & $0.22 \pm 0.12$ & $0.22 \pm 0.08$ & $0.26 \pm 0.07$ & $a, b^{*}, c^{*}$ \\
\hline C20:5 n-3 & $5.39 \pm 0.75$ & $3.97 \pm 1.25$ & $3.16 \pm 0.83$ & $2.78 \pm 0.77$ & $a, b, c$ \\
\hline $\mathrm{C} 23: 0$ & $0.29 \pm 0.18$ & $0.26 \pm 0.14$ & $0.13 \pm 0.04$ & $0.13 \pm 0.04$ & $b^{*}, c, e^{*}$ \\
\hline C22:3 n-3 & $2.40 \pm 0.56$ & $2.60 \pm 0.33$ & $3.25 \pm 1.79$ & $2.66 \pm 0.61$ & NS \\
\hline C22:4 n-6 & $2.67 \pm 0.73$ & $3.37 \pm 0.89$ & $3.96 \pm 0.78$ & $3.95 \pm 0.93$ & $b^{*}, c^{*}$ \\
\hline C24:1 n-9 & $1.14 \pm 0.15$ & $0.70 \pm 0.30$ & $0.34 \pm 0.10$ & $0.37 \pm 0.12$ & $a, b, c, d^{*}, e^{*}$ \\
\hline C22:5 n-3 & $7.68 \pm 0.92$ & $6.56 \pm 1.14$ & $4.56 \pm 0.84$ & $4.33 \pm 0.39$ & $a^{*}, b, c, d, e$ \\
\hline C22:6 n-3 & $15.69 \pm 2.86$ & $23.84 \pm 2.05$ & $20.74 \pm 5.40$ & $21.61 \pm 2.81$ & $a, b^{*}, c$ \\
\hline total SAEA & $29.12 \pm 1.17$ & $29.80 \pm 1.75$ & $32.00 \pm 1.16$ & $34.06 \pm 2.37$ & $\mathrm{~b}, \mathrm{c}, \mathrm{d}, \mathrm{e}$ \\
\hline total MUFA & $22.06 \pm 3.84$ & $18.62 \pm 1.97$ & $19.92 \pm 2.92$ & $20.32 \pm 2.34$ & $\mathrm{a}$ \\
\hline total PUFA & $48.35 \pm 3.90$ & $51.17 \pm 2.10$ & $47.83 \pm 2.56$ & $45.38 \pm 1.74$ & $\mathrm{e}$ \\
\hline total $n-3$ & $32.56 \pm 2.50$ & $38.00 \pm 3.07$ & $32.43 \pm 3.42$ & $32.15 \pm 1.96$ & $\mathrm{a}, \mathrm{d}, \mathrm{e}$ \\
\hline total $n-6$ & $15.78 \pm 3.23$ & $13.17 \pm 2.16$ & $15.40 \pm 2.61$ & $13.23 \pm 2.26$ & NS \\
\hline$n-3 / n-6$ & $2.37 \pm 1.14$ & $2.99 \pm 0.74$ & $2.18 \pm 0.62$ & $2.49 \pm 0.46$ & NS \\
\hline total fat & $3.65 \pm 1.34$ & $3,55 \pm 0,40$ & $3,47 \pm 0,39$ & $3,32 \pm 0,50$ & NS \\
\hline
\end{tabular}

${ }^{a}$ Values are the mean \pm SD. Column "Spp. \& sex" presents significant differences between SolSol-M and SolSol-F (a), between SolSol-F and SolAegF (b), between SolSol-F and SolAeg-M (c), between SolSol-M and SolAeg-F (d), and between SolSol-M and SolAeg-M (e) at $p<0.01$, except in the cases indicated by an asterisk $(p<0.05)$. NS indicates nonsignificant differences. Fatty acids in bold were used in discriminant analysis.

more, stearic (C18:0), nervonic (C24:1 n-9), and docosapentaenoic (C22:5 n-3, DPA) acids were found to exhibit significant differences at both the species level and the sex/ reproductive stage in $S$. solea. A third group of FA included those that exhibited exclusively species-specific differences, with major representatives being palmitic (C16:0), oleic (C18:1 n9c), vaccenic (C18:1 n-7), and linoleic (C18:2 n-6c) acids. No differences were observed in any FA between male and female S. aegyptiaca fish. However, the significance of this finding cannot be evaluated at this point because, as noted above, the female $S$. aegyptiaca sample was limited to only four fish.

The above analysis also revealed that the differences in PUFA and n-3 FA content observed at the species level (Table 1) were due to higher values in these two FA classes in the male $S$. solea fish, as compared to the female fish of the same species as well as to the $S$. aegyptiaca fish, irrespective of sex (Table 2). Thus, from the human nutrition perspective, the higher level of total PUFA and the lower level of total SAFA in S. solea white muscle, as determined in the present study, may render this species more desirable. However, in terms of total fat and n-3/ n-6 FA ratio (Tables 1 and 2) the two species could be considered of equal value.

As mentioned above, sex/reproductive stage-dependent differences of important fatty acids were observed in the $S$. solea sample (Table 2). Of these, the higher concentration of ArA in the female specimens is in accordance with its documented importance in fish reproduction and egg quality ${ }^{24}$ and its accumulation in tissues of spawning fish. ${ }^{25}$ Similarly, the 
Table 3. Summary of the Results of the Forward Step (Step 6) Discriminant Analysis

\begin{tabular}{|c|c|c|c|c|c|}
\hline \multirow[b]{2}{*}{ variable } & \multirow[b]{2}{*}{ Wilks' $\lambda$} & \multirow[b]{2}{*}{$p$} & \multirow[b]{2}{*}{ tolerance } & \multicolumn{2}{|c|}{ standardized coefficients } \\
\hline & & & & root 1 & root 2 \\
\hline C20:0 & 0.026998 & 0.000001 & 0.668299 & 0.44911 & 0.932660 \\
\hline$C 18: 2 n-6 c$ & 0.017978 & 0.000645 & 0.740109 & -0.30636 & 0.731265 \\
\hline C18:1 n-9c & 0.016578 & 0.002266 & 0.750750 & -0.67010 & 0.096680 \\
\hline C16:1 n-7 & 0.015349 & 0.007478 & 0.831833 & 0.58318 & 0.065626 \\
\hline C18:1 n-7 & 0.017006 & 0.001527 & 0.842815 & -0.55507 & 0.380078 \\
\hline $\mathrm{C} 16: 0$ & 0.014127 & 0.027059 & 0.849294 & -0.37843 & 0.371972 \\
\hline \multicolumn{4}{|c|}{ eigenvalue } & 17.99382 & 3.704125 \\
\hline \multicolumn{4}{|c|}{ proportion (\%) } & 83 & 17 \\
\hline
\end{tabular}

lower levels of DHA in the spawning female fish may reflect the selective transfer of this FA to the eggs, as suggested for other fish species. ${ }^{25,26}$ However, detailed comparative analyses in spawning and nonspawning $S$. solea of both sexes are required to evaluate the biological significance of these differences, as well as those concerning the higher EPA and DPA levels in the female spawning fish (Table 2).

Tissue Fatty Acid Composition as a Predictor of Species Identity. In addition to its use as a nutritional quality indicator, tissue FA composition analysis has been applied in recent years to various studies of interest to fisheries and aquaculture, ranging from species discrimination to fish stock identification. ${ }^{19,27,28}$ As clear differences at individual FA levels were established in the two Solea species, we examined whether specific pattern(s) in tissue FA composition could be identified and applied to species and sex/reproductive stage discrimination. To that end, the FA data set was used in discriminant function analysis (DA), a multivariate analysis that is used to determine which continuous variables discriminate between two or more naturally occurring groups. ${ }^{29}$ From this analysis we excluded those FA that exhibited high within-group variances, rendering their statistical significance unreliable. This concerned $10 \mathrm{FA}$, all minor constituents of total FA (cumulative $<6 \%$ of total FA in both species). The remaining 20 FA (bold in Table 2) were employed in forward stepwise DA. In this analysis, all variables were evaluated in a sequential manner to determine which ones contributed most to the discrimination between groups. At each step a variable was selected to be included in the model, and the process was repeated until the addition of a variable violated the significance criterion $(p<$ 0.5 ) for the relationship (canonical correlation) between the variables. Through this process, significant discrimination between the two species and sex/reproductive stage in $S$. solea was reached with the inclusion in the model of six FA, namely, C20:0, C18:2 n-6c, C18:1 n-9c, C16:1 n-7, C18:1 n-7, and C16:0 (Table 2). The Wilk's $\lambda$ and standardized coefficients values presented in Table 3 indicated that C20:0 provided the highest discriminatory power and $\mathrm{C} 16: 0$ the lowest, with canonical root 1 (eigenvalue associated with the canonical function, Table 3) representing $83 \%$ of the variance. Furthermore, the plot of the canonical scores (Figure 2A) revealed that discrimination between species was along root 1 , whereas root 2 discriminated the $S$. solea specimens according to sex/reproductive stage. Projection of the standardized coefficients for each FA on the plane of discriminant functions (Figure 2B) indicated that the tissue content for C18:2 n-6c, C18:1 n-9c, C18:1 n-7, and C16:0 discriminated between the two species, whereas that for C20:0 and C16:1 n-7 discriminated between sex/reproductive stage in $S$. solea in

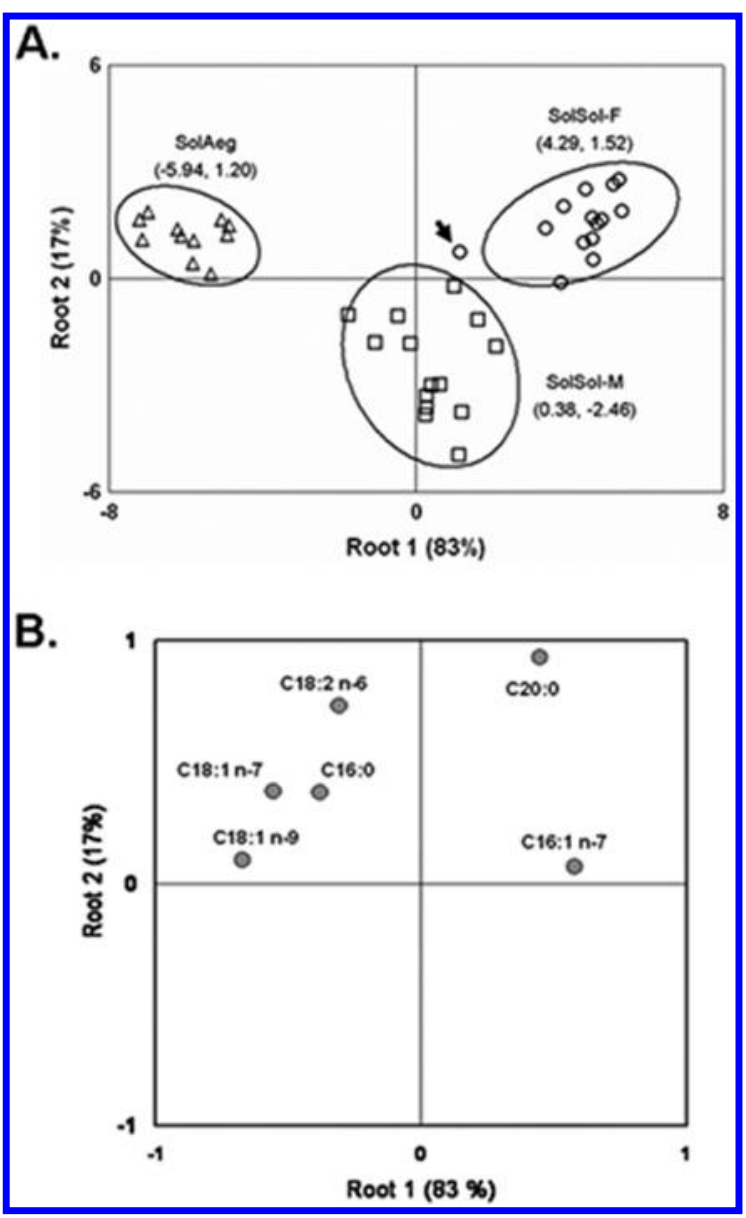

Figure 2. White muscle tissue content for six fatty acids discriminates $S$. solea from S. aegyptiaca.. (A) Plot of canonical scores from discriminant function analysis. S. solea female (SolSol-F) and male (SolSol-M) specimens are represented by circles and squares, respectively; triangles represent the $S$. aegyptiaca (SolAeg) specimens. The means of canonical variables (centroids) are given in parentheses. The arrow indicates the SolSol-F specimen misclassified in crossvalidation. (B) Projection of the standardized coefficients of the six fatty acids along the discriminant functions plane.

addition to discriminating between species. Cross-validation of the DA results for the six FA model identified only a single female $S$. solea (indicated by an arrow in Figure 2A) misclassified as male of the same species (Table 4). The discriminatory power of the six FA model was further tested by random subsampling validation. Irrespective of the size of the validation sample used, which ranged from 20 to $50 \%$ of total 
Table 4. Classification of Individuals According to Species and Sex/Reproductive Stage Prior to and after CrossValidation of the Discriminant Analysis Results of the Six Fatty Acid Data Set ${ }^{a}$

\begin{tabular}{|c|c|c|c|c|c|}
\hline from/to & SolAeg & SolSol-F & SolSol-M & total & $\%$ correct \\
\hline \multicolumn{6}{|c|}{ Estimtion Sample } \\
\hline SolAeg & 11 & 0 & 0 & 11 & 100 \\
\hline SolSol-F & 0 & 14 & 0 & 14 & 100 \\
\hline SolSol-M & 0 & 0 & 14 & 14 & 100 \\
\hline total & 11 & 14 & 14 & 39 & 100 \\
\hline \multicolumn{6}{|c|}{ Cross-Validation Results } \\
\hline SolAeg & 11 & 0 & 0 & 11 & 100 \\
\hline SolSol-F & 0 & 13 & 1 & 14 & 92.86 \\
\hline SolSol-M & 0 & 0 & 14 & 14 & 100 \\
\hline total & 11 & 13 & 15 & 39 & 97.44 \\
\hline
\end{tabular}

cases, this analysis also resulted in $>90 \%$ correct classification according to species and sex/reproductive stage (not shown).

A prerequisite for the utility of phenotypic markers, such as the tissue FA composition, as well as of genetic markers in species discrimination and/or population structure studies, is that they exhibit temporal and spatial stability. Our results provide preliminary evidence for temporal stability in the tissue content of the six FA in S. solea at the local scale. The S. solea sample consisted of individuals collected in two consecutive years (2009 and 2010) with equal numbers of female and male fish in each yearly sample (Supporting Information, Table S1). The values for the tissue content of the six FA in individuals of the same sex did not present significant differences between the two years (Table 5). This is also reflected by the close clustering of the $S$. solea individuals according to sex/ reproductive stage along the discriminant functions of Figure 2. However, it is also important to note that seasonal as well as geographical differences in FA composition have been observed in several fish species including $S$. solea. ${ }^{19,21,30-33}$ Specifically, for the study concerning seasonal FA variation in female $S$. solea $^{21}$ differences were observed in all FA examined, including four of the six FA used in our model. Therefore, it is evident that analysis of additional samples, including seasonal samples of both species as well as samples originating from other geographical areas where the two species live in sympatry, is essential to establish the spatial and temporal stability of the six FA model and, consequently, its potential as a tool for discriminating between the two sibling flatfish species.

\section{ASSOCIATED CONTENT}

\section{Supporting Information}

Details of the samples used in this study (Table S1). This material is available free of charge via the Internet at http:// pubs.acs.org.

\section{AUTHOR INFORMATION}

\section{Corresponding Author}

*Phone: +30 2594029 035. Fax: +30 2594022 222. E-mail: krey@inale.gr.

\section{Funding}

The work leading to these results has received funding from the European Commission's 5th and 7th Framework Programmes under Grant Agreements QLRI-CT-2002-02755 (FishTrace) and KBBE 212399 (FishPopTrace), respectively. G.E.M. acknowledges a postdoctoral fellowship from the Research Foundation-Flanders (FWO-Flanders).

Notes

The authors declare no competing financial interest.

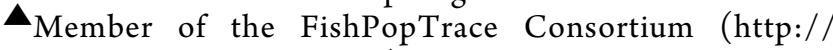
fishpoptrace.jrc.ec.europa.eu/).

Member of the FishTrace Consortium (www.fishtrace.org).

\section{ABBREVIATIONS USED}

Cyt $b$, cytochrome $b$; bp, base pairs; FA, fatty acids; ArA, arachidonic acid; DPA, docosapentaenoic acid; DHA, docosahexaenoic acid; EPA, eicosapentaenoic acid; SAFA, saturated fatty acids; MUFA, monounsaturated fatty acids; PUFA, polyunsaturated fatty acids; DA, discriminant function analysis.

\section{REFERENCES}

(1) FAO Species Fact Sheets. URL (www.fao.org/fishery/species/ 3367/en) (2011)

(2) Espiñeira, M.; González-Lavín, N.; Vieites, J. M.; Santaclara, F. J. Development of a method for the genetic identification of flatfish species on the basis of mitochondrial DNA sequences. J. Agric. Food Chem. 2008, 56, 8954-8961.

(3) Bauchot, M. L. Poissons osseux. In Fiches FAO d'identification pour les besoins de la pêche. (rev. 1). Méditerranée et mer Noire. Zone de pêche 37, Fischer, W., Bauchot, M. L., Schneider, M., Eds.; Commission des Communautés Européennes and FAO: Rome, Italy, 1987; Vol. II, pp 891-1421.

(4) Quéro, J. C.; Desoutter, M.; Lagardere, F. Soleidae. In Fishes of the North-eastern Atlantic and the Mediterranean; Whitehead, P. J., Bauchot, M. L., Hureau, J. C., Nielsen, J., Tortonese, E., Eds.; UNESCO: Paris, France, 1986; Vol. 3, pp 1308-1328.

(5) Ben-Tuvia, A. A taxonomic reappraisal of the AtlantoMediterranean soles Solea solea, S. senegalensis and S. lascaris. J. Fish Biol. 1990, 36, 947-960.

(6) Quignard, J. P.; Pasteur, N.; Shehata, S. Biosystématique du complexe Solea vulgaris du Golfe du Lion (Poissons, Téléostéens, Soléidés). Rev. Trav. Inst. Peches Marit. 1984, 46, 273-284.

Table 5. Interannual Comparisons of White Muscle Tissue Content for the Six Fatty Acids in Female and Male S. solea ${ }^{a}$

\begin{tabular}{|c|c|c|c|c|c|c|c|}
\hline $\operatorname{sex}$ & year & C16:0 & $\mathrm{C} 16: 1 \mathrm{n}-7$ & C18:1 n-7 & $\mathrm{C} 18: 1 \mathrm{n}-9 \mathrm{c}$ & $C 18: 2 n-6 c$ & C20:0 \\
\hline $\mathrm{F}$ & $2009(n=8)$ & $19.33 \pm 1.46$ & $4.49 \pm 0.98$ & $2.25 \pm 0.34$ & $8.97 \pm 0.93$ & $0.82 \pm 0.38$ & $1.03 \pm 0.28$ \\
\hline \multirow[t]{2}{*}{$\mathrm{F}$} & $2010(n=6)$ & $18.31 \pm 1.87$ & $4.02 \pm 0.44$ & $2.42 \pm 0.81$ & $10.29 \pm 2.23$ & $0.69 \pm 0.36$ & $1.05 \pm 0.29$ \\
\hline & $p$ & 0.272 & 0.287 & 0.612 & 0.154 & 0.515 & 0.895 \\
\hline $\mathrm{M}$ & $2009(n=8)$ & $20.12 \pm 1.96$ & $2.52 \pm 0.37$ & $2.30 \pm 0.43$ & $8.42 \pm 0.99$ & $0.61 \pm 0.10$ & $0.38 \pm 0.15$ \\
\hline \multirow[t]{2}{*}{$\mathrm{M}$} & $2010(n=6)$ & $20.30 \pm 1.87$ & $2.69 \pm 0.38$ & $2.28 \pm 0.53$ & $9.31 \pm 0.66$ & $0.61 \pm 0.25$ & $0.54 \pm 0.19$ \\
\hline & $p$ & 0.837 & 0.412 & 0.914 & 0.081 & 0.988 & 0.124 \\
\hline
\end{tabular}

${ }^{a}$ Values are the mean $\pm \mathrm{SD}$. 
(7) Goucha, M.; She, J. X.; Kotulas, G.; Mathieu, E.; Renno, J. F.; Pasteur, N. Biosystematics and genetic relationships of Solea aegyptiaca and S. senegalensis. Biochem. Syst. Ecol. 1987, 15, 699-708.

(8) She, J. X.; Autem, M.; Kotulas, G.; Pasteur, N.; Bonhomme, F. Multivariate analysis of genetic exchanges between Solea aegyptiaca and Solea senegalensis (Teleosts, Soleidae). Biol. J. Linnean Soc. 1987, 32, 357-371.

(9) Borsa, P.; Quignard, J. P. Systematics of the AtlanticMediterranean soles Pegusa impar, P. lascaris, Solea aegyptiaca, S. senegalensis, and S. solea (Pleuronectiformes: Soleidae). Can. J. Zool. 2001, 79, 2297-2302.

(10) Vachon, J.; Chapleau, F.; Desoutter-Meniger, M. Révision du genre Solea et réhabilitation du genre Barnardichthys (Soleidae; Pleuronectiformes). Cybium 2008, 32, 9-26.

(11) Desoutter, M. Soleidae. In Check-list of the Fishes of the Eastern Tropical Atlantic (CLOFETA); Quero, J. C., Hureau, J. C., Karrer, C., Post, A., Saldanha, L., Eds.; JNICT/SEI/UNESCO: Paris, France, 1990; Vol. 2, pp 1037-1049.

(12) Pagotto, G. Presenza di Solea vulgaris forma aegyptiaca (Chabanaud 1927) in alto Adriatico. Arch. Oceanogr. Limnol. 1971, 17, 179-183.

(13) Mehanna, S. F. Stock assessment and management of the Egyptian sole Solea aegyptiaca, Chabanaud, 1927 (Osteichthyes: Soleidae), in the Southeastern Mediterranean, Egypt. Turk. J. Zool. 2007, 31, 379-388.

(14) Ogden, R. Fisheries forensics: the use of DNA tools for improving compliance, traceability and enforcement in the fishing industry. Fish Fish. 2008, 9, 462-472.

(15) Ouanes, K.; Bahri-Sfar, L.; Ben Hassine, O. K.; Bonhomme, F. Expanding hybrid zone between Solea aegyptiaca and Solea senegalensis: genetic evidence over two decades. Mol. Ecol. 2011, 20, 1717-1728.

(16) Sevilla, R. G.; Diez, A.; Noren, M.; Mouchel, O.; Jérôme, M.; Verrez-Bagnis, V.; van Pelt, H.; Favre-Krey, L.; Krey, G.; Bautista, J. M. The FishTrace Consortium Primers and polymerase chain reaction conditions for DNA barcoding teleost fish based on the mitochondrial cytochrome b and nuclear rhodopsin genes. Mol. Ecol. Notes 2007, 7, 730-734.

(17) Tamura, K.; Peterson, D.; Peterson, N.; Stecher, G.; Nei, M.; Kumar, S. MEGA5: molecular evolutionary genetics analysis using maximum likelihood, evolutionary distance, and maximum parsimony methods. Mol. Biol. Evol. 2011, 28, 2731-2739.

(18) Folch, J.; Less, M.; Sloan Stanley, G. H. A simple method for the isolation and purification of total lipids from animal tissues. J. Biol. Chem. 1957, 226, 497-509.

(19) Falch, E.; Rustad, T.; Jonsdottir, R.; Shawd, N. B.; Dumay, J.; Berge, J. P.; Arason, S.; Kerry, J. P.; Sandbakk, M.; Aursand, M. Geographical and seasonal differences in lipid composition and relative weight of by-products from gadiform species. J. Food Compos. Anal. 2006, 19, 727-736.

(20) Soriguer, F.; Serna, S.; Valverde, E.; Hernando, J.; Martín-Reyes, A.; Soriguer, M.; Pareja, A.; Tinahones, F.; Esteva, I. Lipid, protein, and calorie content of different Atlantic and Mediterranean fish, shellfish, and molluscs commonly eaten in the south of Spain. Eur. J. Epidemiol. 1997, 13, 451-463.

(21) Gökçe, M. A.; Taşbozan, O.; Çelik, M.; Tabakoğlu, Ş.S. Seasonal variations in proximate and fatty acid compositions of female common sole (Solea solea). Food Chem. 2004, 88, 419-423.

(22) Pacetti, D.; Alberti, F.; Boselli, E.; Frega, N. G. Characterisation of furan fatty acids in Adriatic fish. Food Chem. 2010, 122, 209-215. (23) Simopoulos, A. P. Importance of the ratio of omega-6/omega-3 essential fatty acids: evolutionary aspects. World Rev. Nutr. Diet. 2003, 92, 1-174.

(24) Bell, J. G.; Sargent, J. R. Arachidonic acid in aquaculture feeds: current status and future opportunities. Aquaculture 2003, 218, 491499.

(25) Huynh, M. D.; Kitts, D. D.; Hu, C.; Trites, A. W. Comparison of fatty acid profiles of spawning and non-spawning Pacific herring, Clupea harengus pallasi. Comp. Biochem. Phys. B 2007, 146, 504-511.
(26) Tocher, R. D. Metabolism and functions of lipids and fatty acids in teleostfish. Rev. Fish. Sci. 2003, 11, 107-184.

(27) Joensen, H.; Grahl-Nielsen, O. Discrimination of Sebastes viviparus, Sebastes marinus and Sebastes mentella from Faroe Islands by chemometry of the fatty acid profile in heart and gill tissues and in the skull oil. Comp. Biochem. Phys. B 2000, 126, 69-79.

(28) Bell, J. G.; Preston, T.; Henderson, R. J.; Strachan, F.; Bron, J. E.; Cooper, K.; Morrison, D. J. Discrimination of wild and cultured European sea bass (Dicentrarchus labrax) using chemical and isotopic analyses. J. Agric. Food Chem. 2007, 55, 5934-5941.

(29) McLachlan, G. J. Discriminant analysis and statistical pattern recognition. John Wiley \& Sons, Inc.: Hoboken, NJ, 2004.

(30) Shirai, N.; Terayama, M.; Tekada, H. Effect of season the fatty acid composition and free amino acid content of the sardine Sardinops melanostictus. Comp. Biochem. Phys. B 2002, 131, 387-393.

(31) Shirai, N.; Suzuki, H.; Tokairin, S.; Ehara, H.; Wada, S. Dietary and seasonal effects on the dorsal meat lipid composition of Japanese (Silurus asotus) and Thai catfish (Clarias macrocephalus and hybrid Clarias macrocephalus and Clarias galipinus). Comp. Biochem. Phys. A 2002, 132, 609-619.

(32) Senso, L.; Suárez, M. D.; Ruiz-Cara, T.; García-Gallego, M. On the possible effects of harvesting season and chilled storage on the fatty acid profile of the fillet of farmed gilthead sea bream (Sparus aurata). Food Chem. 2007, 101, 298-307.

(33) Henderson, R. J.; Almatar, S. M. Seasonal changes in the lipid composition of herring (Clupea harengus) in relation to gonad maturation. J. Mar. Biol. Assoc. U.K. 1989, 69, 323-334. 